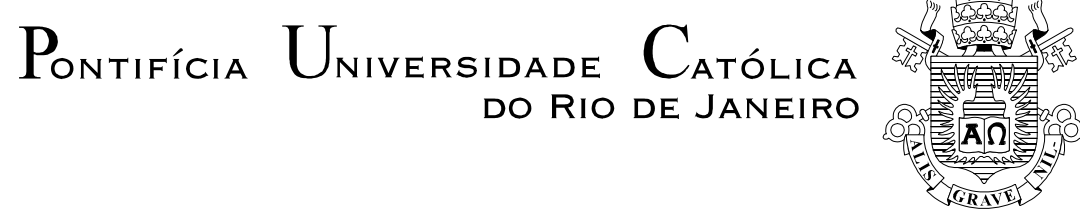

Cid Merlino Fernandes

Vergonha: A revelação da catástrofe
narcísica - para uma compreensão
da clínica contemporânea

Tese de Doutorado

Tese apresentada ao Programa de Pós-graduação em Psicologia do Departamento de Psicologia da PUC-Rio como parte dos requisitos parciais para obtenção do título de Doutor em Psicologia Clínica.

Orientadora: Profa. Ana Maria Rudge

Rio de Janeiro

Janeiro de 2006 


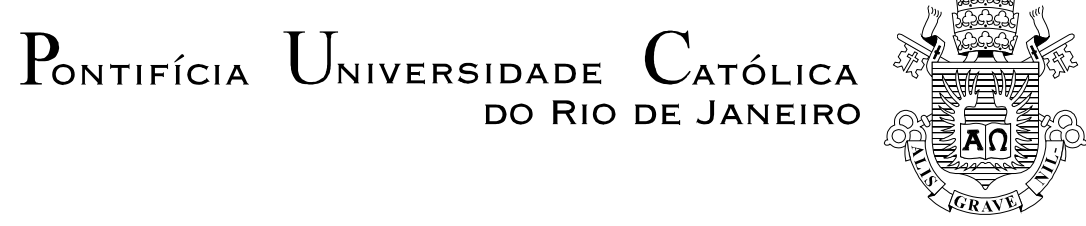

Cid Merlino Fernandes

\title{
Vergonha: A revelação da catástrofe narcísica - para uma compreensão da clínica contemporânea
}

Tese apresentada como requisito parcial para obtenção do grau de Doutor pelo Programa de Pós-Graduação em Psicologia Clínica do Departamento de Psicologia do Centro de Teologia e Ciências Humanas da PUC-Rio. Aprovada pela Comissão Examinadora abaixo assinada.

\author{
Profa. Ana Maria Rudge \\ Orientadora \\ Departamento de Psicologia - PUC-Rio \\ Profa. Junia de Vilhena \\ Departamento de Psicologia - PUC-Rio \\ Profa . Silvia Maria Abu-Jamra Zornig \\ Departamento de Psicologia - PUC-Rio
}

Prof $^{a}$. Maria Teresa da Silveira Pinheiro Instituto de Psicologia - UFRJ

Prof. Manoel Tosta Berlinck Departamento de Psicologia - PUC-SP

Prof. Paulo Fernando Carneiro de Andrade Coordenador Setorial de Pós-Graduação e Pesquisa do Centro de Teologia e Ciências Humanas - PUC-Rio

Rio de Janeiro, / /200 
Todos os direitos reservados. É proibida a reprodução total ou parcial do trabalho sem autorização da universidade, do autor e da orientadora.

\section{Cid Merlino Fernandes}

Graduou-se em Medicina na Faculdade de Medicina de Petrópolis em 1979. Trabalhou como médico generalista no campo da Clínica Médica. Foi plantonista e médico assistente em hospitais psiquiátricos na cidade de Petrópolis. Fez formação psicanalítica na Sociedade de Psicanálise da Cidade do Rio de Janeiro - SPCRJ. Foi membro do Advisory Board da revista Addiction Alert. Dirigiu o CREDEQ - Centro de Recuperação para dependentes Químicos. É psicanalista e psiquiatra em atividade privada e é Diretor Clínico da SPCRJ, tendo feito mestrado na PUC-Rio.

Ficha Catalográfica

Fernandes, Cid Merlino

Vergonha : a revelação da catástrofe narcísica - para uma compreensão da clínica contemporânea / Cid Merlino Fernandes ; orientador: Ana Maria Rudge. - Rio de Janeiro : PUC, Departamento de Psicologia, 2006.

185 f. ; $30 \mathrm{~cm}$

Tese (doutorado) - Pontifícia Universidade Católica do Rio de Janeiro, Departamento de Psicologia.

Inclui referências bibliográficas.

1. Psicologia - Teses. 2. Melancolia. 3. Vergonha. 4. Contemporaneidade. 5. Psicanálise. 6. Vazio. 7. Insuficiência. I. Rudge, Ana Maria. II. Pontifícia Universidade Católica do Rio de Janeiro. Departamento de Psicologia. III. Título. 
Para minha paixão Fernanda e as adoráveis filhas Flavia, Julia e Rachel. 


\section{Agradecimentos}

À orientadora Ana Maria Rudge pela parceria e pela confiança constituídas de forma séria e sempre elegante.

À CAPES e à PUC-Rio, pelos auxílios concedidos, sem os quais este trabalho não poderia ter sido realizado.

À Lindinaura Canosa e Denise Ripper, fiéis interlocutoras.

Ao Grupo de Pesquisa da PUC-Rio que ao longo dos anos forneceu comentários essenciais para o desenvolvimento das idéias apresentadas.

À Teresa Pinheiro e Julio Verztman, assim como o Grupo de Pesquisa da UFRJ, da Teoria Psicanalítica, que generosamente permitiram minha participação nos estudos que serviram de fundamento para esta tese.

Ao Joel Birman e aos amigos do Grupo de Estudos que me ajudaram a desenvolver uma leitura crítica da Psicanálise.

À Sociedade de Psicanálise da Cidade do Rio de Janeiro - SPCRJ pela transmissão de uma psicanálise livre e não dogmática.

Às secretárias do Departamento de Pós-graduação da PUC-Rio, Vera e Marcelina, que nunca economizaram seus sorrisos e as palavras de incentivo.

Aos professores da PUC-Rio pelos rastros deixados em minhas reflexões.

Aos meus amigos de hoje e sempre que me ensinam, um dia de cada vez, o valor do bom-humor e da seriedade. Nomeá-los tomaria incontáveis folhas.

À Angela Lobo, amiga especial.

Aos meus clientes, fonte de inspiração de cada linha escrita nesta tese.

À Regina Assis, sempre presente em minha vida.

À minha bem-humorada família que, sem exceção, me mostra os efeitos do amor recíproco e da união.

Ao meu pai Carlos (in memorium) pela falta sentida, tornada alegre presença em todos os momentos de minha vida. 


\section{Resumo}

Fernandes, Cid Merlino; Rudge, Ana Maria (Orientadora) Vergonha: a revelação da catástrofe narcísica - para uma compreensão da clínica contemporânea. Rio de Janeiro, 2006. 185p. Tese de Doutorado Departamento de Psicologia, Pontifícia Universidade Católica do Rio de Janeiro.

A histeria foi usada como modelo para expressar uma forma de sofrimento psíquico típica do final do século XIX. Esta tese se propõe a justificar o uso da melancolia como a formação psíquica mais adequada para traduzir a forma de padecimento psíquico atual. Para isso é empreendido um aprofundamento na teoria freudiana a respeito da circunscrição deste quadro. Para demonstração da pertinência desta proposta o afeto da vergonha é destacado e analisado. O problema narcísico articulado ao desenvolvimento deste afeto e sua particularidade na melancolia são mencionados como pontos de aproximação com os ruídos clínicos atuais e com uma forma própria do homem de hoje lidar com a idéia de não se bastar e precisar do outro.

\section{Palavras-chave}

Melancolia; vergonha; contemporaneidade; psicanálise; vazio; insuficiência 


\section{Abstract}

Fernandes, Cid Merlino; Rudge, Ana Maria (Advisor). Shame: the revelation of the narcissistic catastrophe - for an understanding of contemporary clinic. Rio de Janeiro, 2006. 185p. Thesis of Doctorate Departamento de Psicologia, Pontifícia Universidade Católica do Rio de Janeiro.

Histery was used as model to express the typical form of psychic suffering of the end of century XIX. This thesis tries to justify the use of the melancholy as a psychic formation more adjusted to approach the form of the contemporary psychic suffering. For this a study on Freudian theory regarding the circumscription of this affection is undertaken. To demonstrate the relevancy of this proposal, the affect of the shame is circumscribed and analyzed. The narcissistic problem related to the development of this affect and its specificity in melancholy are taken as points of approach to the current clinical questions and a proper form of the man today to deal with the idea of not being enough themselves and needing other people.

\section{Keywords}

Melancholy; Shame; Contemporariness; Psychoanalysis; emptiness; Insufficiency. 


\section{Sumário}

$\begin{array}{ll}\text { 1. Introdução } & 10\end{array}$

$\begin{array}{ll}\text { 2. Primeiras observações sobre a Melancolia } & 17\end{array}$

3. Luto e Melancolia: um marco 31

4. A neurose narcísica 46

5. As contribuições de Karl Abraham 60

6. O Narcisismo e suas conseqüências 69

6.1. Freud - O Narcisismo como organização permanente 70

6.2. Winnicott - A mãe no espelho 77

6.3. Lacan: A metáfora do espelho 86

7. O Sujeito melancólico 93

7.1. O vazio melancólico 94

7.2. A problemática dos Ideais $\quad 100$

7.3. O Negativismo melancólico 111

8. Vergonha: um critério diferenciador para a Atualidade 122

8.1. Considerações freudianas sobre a vergonha 123

8.2. Vergonha e culpa 136

8.3. A cultura da vergonha 139

8.4. Considerações atuais sobre a vergonha 143

8.5. A vergonha e a insuficiência - o relevo no narcisismo 155

8.6. Vergonha: a revelação da catástrofe narcísica 158

9. Considerações finais 162

$\begin{array}{ll}\text { 10. Bibliografia } & 175\end{array}$ 
Sempre uma coisa defronte da outra, Sempre uma coisa tão inútil como a outra, Sempre o impossível tão estúpido como o real, Sempre o mistério do fundo tão certo como o sono de mistério da superfície, Sempre isto ou sempre outra coisa ou nem uma coisa nem outra.

Álvaro Campos, Tabacaria 